\title{
Co-Gd Phosphonate Complexes as Magnetic Refrigerants
}

\author{
Yan-Zhen Zheng, ${ }^{a}$ Marco Evangelisti ${ }^{b}$ and Richard E. P. Winpenny,c* \\ Received (in $X X X, X X X) X$ th $X X X X X X X X X 200 X$, Accepted Xth $X X X X X X X X X 200 X$ \\ First published on the web $X$ th $X X X X X X X X X 200 X$ \\ ${ }_{5}$ DOI: 10.1039/b000000x
}

Three 3d-4f complexes, $\left[\mathrm{Co}_{8}{ }^{\mathrm{II}_{3}} \mathrm{Gd}^{\mathrm{III}}{ }_{8}\left(\mu_{3}-\mathrm{OH}\right)_{4}\left(\mathrm{NO}_{3}\right)_{4}\left(\mathrm{O}_{2} \mathrm{C}{ }^{t} \mathrm{Bu}\right)_{16}\right.$ $\left.\left(\mathrm{O}_{3} \mathrm{P}^{t} \mathrm{Bu}\right)_{8}\right], \quad\left[\mathrm{Co}_{8}{ }_{8} \mathrm{Gd}^{\mathrm{III}}{ }_{4}\left(\mathrm{O}_{3} \mathrm{P}^{t} \mathrm{Bu}\right)_{6}\left(\mathrm{O}_{2} \mathrm{C}{ }^{t} \mathrm{Bu}\right)_{16}\right]$ and $\left[\mathrm{Co}_{4}{ }_{4} \mathrm{Gd}^{\mathrm{III}} 6\right.$ $\left.\left(\mathrm{O}_{2} \mathrm{C}^{t} \mathrm{Bu}\right)_{14}\left(\mathrm{O}_{3} \mathrm{PCH} \mathrm{H}_{2} \mathrm{Ph}\right)_{6}(\mathrm{MeCN})_{2}\right]$, have been synthesized and have structures that can be related to molecular grids. Magnetic 10 studies show they have promise as low temperature magnetic refrigerants.

One of the most promising areas for application of molecular nanomagnets (MNMs) is in the area of low temperature magnetic cooling. ${ }^{1-4}$ Early examples of such studies looked at highly

15 anisotropic single molecule magnets, ${ }^{5}$ but studies by McInnes and co-workers ${ }^{1}$ have shown that high spin, highly isotropic spin clusters are most promising. Very recent work by Karotsis et al has shown remarkable results for a $\left\{\mathrm{Mn}_{4} \mathrm{Gd}_{4}\right\}$ complex stabilized by calixarene ligands. ${ }^{4}$ Here we report a second family of 3d-4f 20 complexes which show remarkable changes in entropy with changing field, which should be equally promising for magnetic cooling. While the structures are heterometallic, in many ways the closest structural analogues in the literature are the very beautiful paramagnetic grids reported by the Thompson group ${ }^{6}$ 25 and by Lehn and Ruben. ${ }^{7}$

Here we report the first family of $3 \mathrm{~d}-4 \mathrm{f}$ molecular squares $\left[\mathrm{Co}_{8} \mathrm{II}_{8} \mathrm{Gd}^{\mathrm{III}} 8\left(\mu_{3}-\mathrm{OH}\right)_{4}\left(\mathrm{NO}_{3}\right)_{4}\left(\mathrm{O}_{2} \mathrm{C}^{t} \mathrm{Bu}\right)_{16}\left(\mathrm{O}_{3} \mathrm{P}^{t} \mathrm{Bu}\right)_{8}\right] \mathbf{1}, \quad\left[\mathrm{Co}_{8}{ }_{8} \mathrm{Gd}^{\mathrm{III}}{ }_{4}\right.$ $\left.\left(\mathrm{O}_{3} \mathrm{P}^{t} \mathrm{Bu}\right)_{6}\left(\mathrm{O}_{2} \mathrm{C}{ }^{t} \mathrm{Bu}\right)_{16}\right] 2$ and $\left[\mathrm{Co}^{\mathrm{II}}{ }_{4} \mathrm{Gd}^{\mathrm{III}}{ }_{6}\left(\mathrm{O}_{2} \mathrm{C}{ }^{t} \mathrm{Bu}\right)_{14}\left(\mathrm{O}_{3} \mathrm{PCH}{ }_{2} \mathrm{Ph}\right)_{6}\right.$ $(\mathrm{MeCN})_{2}$ ] 3 which have structures related to, albeit distorted 30 from, grids. These compounds were synthesized from two precursors, $\quad\left[\mathrm{Co}_{2} \mathrm{II}_{2}\left(\mu-\mathrm{OH}_{2}\right)\left(\mathrm{O}_{2} \mathrm{C}^{t} \mathrm{Bu}\right)_{4}\right] \cdot\left(\mathrm{HO}_{2} \mathrm{C}^{t} \mathrm{Bu}\right)_{4} \quad 4^{8} \quad$ and $\left[\mathrm{Gd}_{2}\left(\mathrm{O}_{2} \mathrm{C}^{t} \mathrm{Bu}\right)_{6}\left(\mathrm{HO}_{2} \mathrm{C}^{t} \mathrm{Bu}\right)_{6}\right]$ 5. The structure of $\mathbf{5}$ is identical with the reported $\left[\mathrm{Ln}_{2}\left(\mathrm{O}_{2} \mathrm{C}^{t} \mathrm{Bu}\right)_{6}\left(\mathrm{HO}_{2} \mathrm{C}^{t} \mathrm{Bu}\right)_{6}\right]$ analogues $\left(\mathrm{Ln}=\right.$ ???). ${ }^{9}$

Compound 1 crystallised in the monoclinic space group ${ }_{35} \mathrm{C} 2 / \mathrm{c}$. The $C_{2}$ axis passes the diagonal the square, generating the whole molecule from the asymmetric unit, which comprises of half the molecular formula (Figure 1). The centre of the molecule features a $[2 \times 2]\left\{\mathrm{Co}_{4}\right\}$ square grid in which six-coordinate cobalt(II) ions are bridged by four 402.210 nitrates (Harris notation ${ }^{10}$ ) that are disordered about the $C_{2}$ axis with alternating up and down orientations. The Co $\cdots$ Co distances within the $\left[\mathrm{Co}_{4}\right]$ grid are in the range of 4.26 to $4.33 \AA$. Such $[2 \times 2] \mathrm{M}_{4}$ grids are not rare and have been reported for cobalt(II), copper(II), nickel(II) and 45 manganese(II) compounds. ${ }^{11}$ The phosphonate ligands show a 4.122-coordination mode that bridge between the inner $\left\{\mathrm{CO}_{4}\right\}$ square and an outer $\left\{\mathrm{Gd}_{8} \mathrm{Co}_{4}\right\}$ frame. Four $\mu_{3}-\mathrm{OH}$ groups bridge between each vertex of the $\left\{\mathrm{Co}_{4}\right\}$ square and two adjacent $\mathrm{Gd}(\mathrm{III})$ ions, forming a $\left[\mathrm{CoGd}_{2}\left(\mu_{3}-\mathrm{OH}\right)\right]$ triangle. 50 The Co $\cdots \mathrm{Gd}$ separations in this triangle are in the range of 3.48 to $3.53 \AA$ and the $\mathrm{Gd} \cdots \mathrm{Gd}$ separation is $3.575($ ?) $\AA$. The four corner cobalt(II) ions of the outer $\left[\mathrm{Gd}_{8} \mathrm{Co}_{4}\right]$ square are four-coordinate with two oxygen atoms from two phosphonates and the other two oxygen atoms from two ${ }_{55}$ pivalates. The Co $\cdots \mathrm{Gd}$ separations in the outer [ $\left.\mathrm{Gd}_{8} \mathrm{Co}_{4}\right]$ square are in the range of 3.646-3.920 $\AA$, which are slightly longer than the inner Co $\cdots \mathrm{Gd}$ separations.

Compared with a regular $[4 \times 4]$ grid the central $\left\{\mathrm{Co}_{4}\right\}$ square is rotated through $45^{\circ}$ with respect to the outer $60\left\{\mathrm{Gd}_{8} \mathrm{Co}_{4}\right\}$ frame. The structure is slightly bowed rather than completely planar (for detail, see the side view in Figure S1).

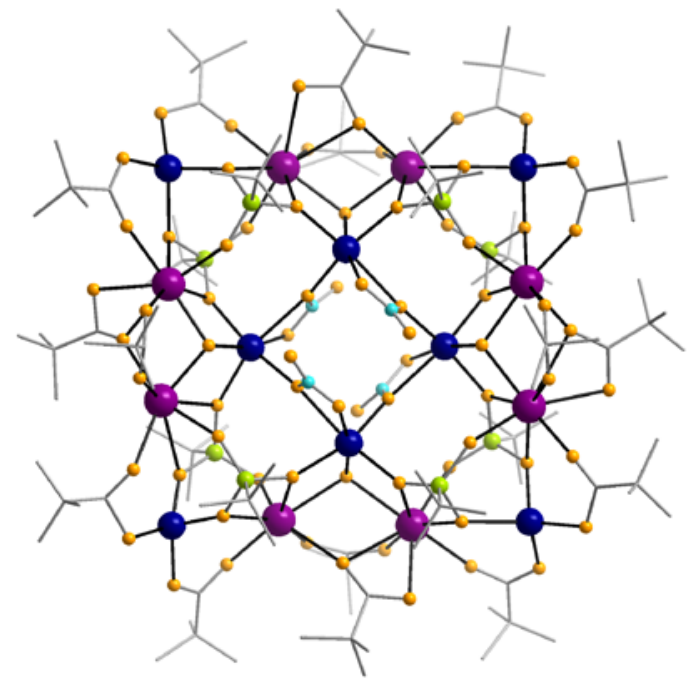

Fig. 1 Perspective view of 1 . Colour codes: Ln, purple; Co, blue; P, green; O, orange; $\mathrm{N}$, cyan; C, grey.

65 The crystal structure of 2, which has two-fold symmetry, features a [ $4 \times 3$ ] grid structure (Figure 2). The outer rows of four metals are symmetry equivalent, and each contains two five-coordinate terminal $\mathrm{Co}$ (II) ions which are triply bridged with the two central $\mathrm{Gd}(\mathrm{III})$ ions by one 2.21 carboxylate, 70 one 2.11 carboxylate and one oxygen from a 4.221 phosphonate. The Co $\cdots$ Gd separations are ca. $3.64 \AA$. The two central Gd(III) ions are also triply bridged by an oxygen from a 4.222 phosphonate and two 2.11 pivalates with a Gd $\cdots$ Gd separation of $4.21 \AA$. The central row of the grid 75 contains four four-coordinate Co(II) ions and they are bridged by 4.221 and 4.222 phosphonates (Figure 2). The three Co $\cdots$ Co separations within the central row are 4.322 or 4.782 $\AA$. The metal-metal distances between the rows are shorter (3.343-3.356 $\AA$ ). The metal sites in compound 2 lie in a single 80 plane (Figure $\mathrm{S} 2$ ). 


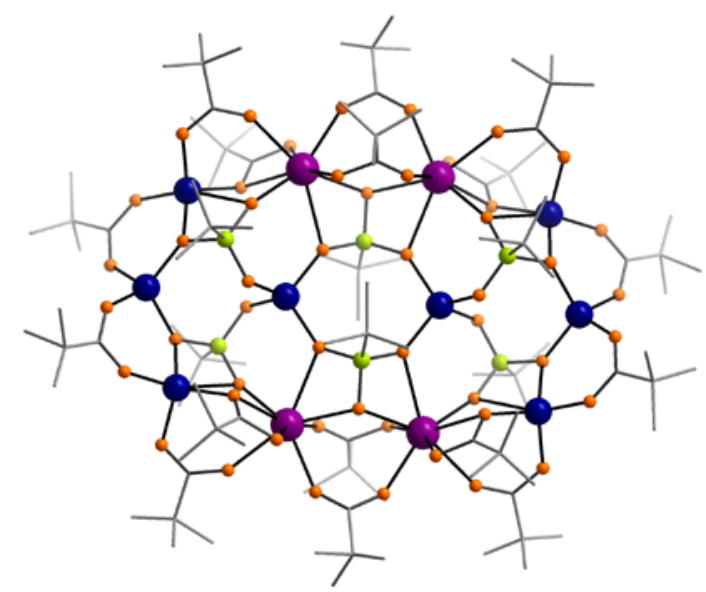

Fig. 2 Perspective view of 2 . Colour codes: Ln, purple; Co, blue; P, green; O, orange; $\mathrm{N}$, cyan; C, grey.

Compound 3 has a pair of octahedal Co(II) ions in the 5 centre, which are surrounded by six Gd(III) ions and two tetrahedal $\mathrm{Co}(\mathrm{II})$ ions. If the central $\mathrm{Co}(\mathrm{II})$ dimer were regarded as a "node", this molecule would be a [3 $\times 3$ ] grid. The molecule itself has two-fold symmetry, that is, by cutting through the diagonals of the square half the molecule can be 10 reflected and overlapped with the other half. The central $\mathrm{Co}(\mathrm{II})$ dimer is part of a $\mathrm{Co}_{2} \mathrm{O}_{2}$ ring, with the oxygen atoms coming from two 5.222 phosphonates; the Co $\cdots$ Co separation is 3.190(?) A. Each Gd $\cdots \mathrm{Gd}$ edge is triply-bridged by an oxygen from a 4.221 phosphonate and two 2.11 pivalates with ${ }_{15} \mathrm{Gd} \cdots \mathrm{Gd}$ separations of either 4.051 or $4.076 \AA$. The corner tetrahedral Co(II) ions are doubly-bridged to the adjacent Gd ions by one 2.11 pivalate and one O-atom from a 4.221 phosphonate with a Co $\cdots$ Gd separations of $c a .3 .68 \AA$. Each of the central $\mathrm{Co}(\mathrm{II})$ ions is bridged to two Gd ions by two O20 atoms from two 4.221 phosphonates with Co $\cdots$ Gd separations of ca. $4.07 \AA$. The metal sites in compound 3 all lie in one plane (Figure S3), except for the central two cobalt sites which lie X.XX $\AA$ out of the plane.

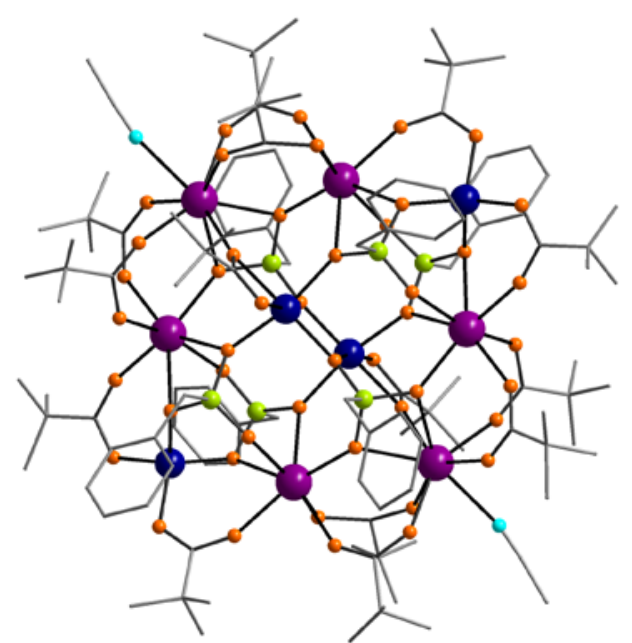

Fig. 3 Perspective view of 3. Colour codes: Ln, purple; Co, blue; P, green; O, orange; $\mathrm{N}$, cyan; $\mathrm{C}$, grey.

Compounds $\mathbf{2}$ and $\mathbf{3}$ are made from very similar reactions, differing only in the phosphonate used; this seems to have a significant impact on the structure. The ${ }^{t} \mathrm{BuPO}_{3}$ in both both 1 30 and 2 adopt either [4.221] or [4.222] binding modes. In contrast, the $\mathrm{PhCH}_{2} \mathrm{PO}_{3}$ used in 3 either [5.222] or [4.221] coordination modes. The difference is probably due to the different steric requirements of the benzyl group.

The magnetic behaviour of $\mathbf{1}$ to $\mathbf{3}$ has been studied on 35 polycrystalline samples. At room temperature, the $\chi_{M} T$ value of 1 is 82.7 emu K mol-1 (Figure 4), which is consistent with the spin-only value (78.0 emu $\mathrm{K} \mathrm{mol}^{-1}$ ) for eight cobalt(II) ions $(S=3 / 2)$ and eight gadolinium(III) ions $(S=7 / 2)$ if considering the orbital contribution from four octahedral 40 cobalt(II) ions. Upon cooling, the $\chi_{M} T$ vs. $T$ curve decreases steadily with decreasing temperature to a value around 41.5 emu $\mathrm{K} \mathrm{mol}^{-1}$ at $2 \mathrm{~K}$, indicating a non-diamagnetic ground state. This decrease is probably due to a mixture of antiferromagnetic coupling between the metal centres and 45 single ion effects for the cobalt(II) centres. ${ }^{13}$ Fitting the data between 300 and $100 \mathrm{~K}$ with Curie-Weiss law gives a Curie constant, $C$, of 87.0 emu $\mathrm{mol}^{-1} \mathrm{~K}$ and a Weiss constant, $\theta$ of $16.3 \mathrm{~K}$. Magnetisation measurements at low temperatures (2 to $6 \mathrm{~K}$ ) were also performed (insert of Figure 4). The steady 50 increase of the $M$ vs. $H$ plots reaches $61.2 \mu_{\mathrm{B}}$ at $7 \mathrm{~T}$ at $2 \mathrm{~K}$ but does not saturate; the value is below that expected for the maximum paramagnetic state of $80 \mu_{\mathrm{B}}$ for eight spin-only cobalt(II) and eight gadolinium(III) ions, ${ }^{14}$ again indicates possibly antiferromagnetic interactions within the cluster.

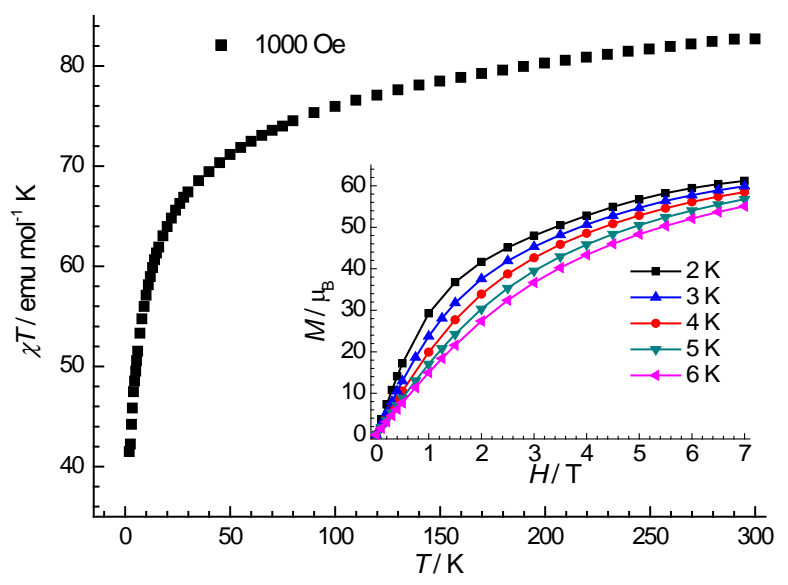

Fig. 4 The $\chi T$ vs. $T$ plot of $\mathbf{1}$ under 1000 Oe dc field. Inset: the fileddependent magnetization plots at indicated temperatures.

For 2, the the room temperature $\chi_{M} T$ value of $54.6 \mathrm{emu} \mathrm{K}$ $\mathrm{mol}^{-1}$ is consistent with which is consistent with the spin-only 60 value (46.5 emu $\mathrm{K} \mathrm{mol}^{-1}$ ) of eight cobalt(II) ions and four gadolinium(III) ions if considering the orbital contribution from four pseudo-octahedral cobalt(II) ions. Upon cooling, the $\chi_{M} T$ vs. $T$ curve decreases steadily with decreasing temperature to a value around $36.1 \mathrm{emu} \mathrm{K} \mathrm{mol}^{-1}$ at $2 \mathrm{~K}$, which 65 also indicates a non-diamagnetic ground state. Fitting the data between 300 and $100 \mathrm{~K}$ with Curie-Weiss law gives a $C$ value of 57.1 emu $\mathrm{mol}^{-1} \mathrm{~K}$ and a $\theta$ value of $-14.7 \mathrm{~K}$. The $C$ value correponds to a $g$ value of 2.22, which is again likely to be a result of crystal field effects from the pseudo-octahedral 70 cobalt(II) centres and the moderate negative $\theta$ value might be due to the additional mixture of antiferromagnetic interactions within metal centres. $M$ vs. $H$ plots at 2 and $4 \mathrm{~K}$ (insert of Fig. 
5) also show a steady increase that reaches $39.2 \mu_{\mathrm{B}}$ at $7 \mathrm{~T}$ at 2 K without saturation.

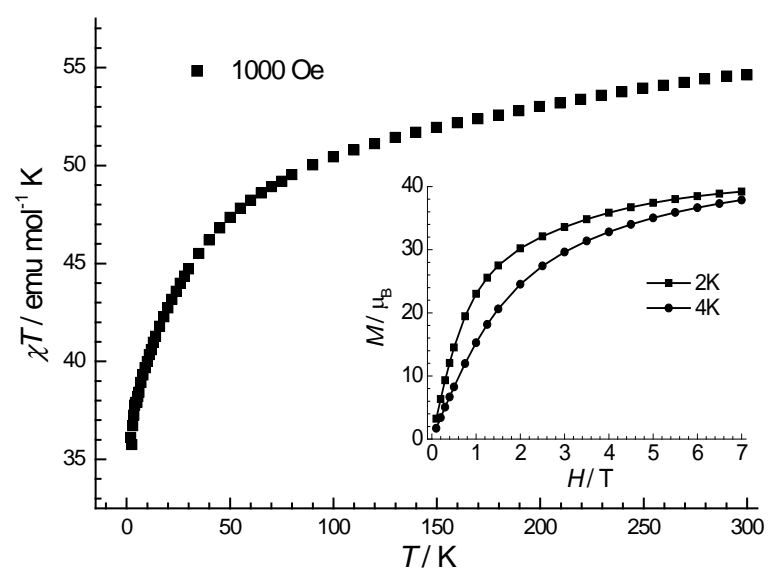

Fig. 5 The $\chi T$ vs $T$ plot of 2 under 1000 Oe dc field. Inset: the fileddependent magnetization plots at indicated temperatures.

For compound 3, $\chi_{M} T$ shows a value of $61.6 \mathrm{emu} \mathrm{K} \mathrm{mol}^{-1}$ at $300 \mathrm{~K}$ (Figure 6) that is larger than the spin-only value of 54.8 emu $\mathrm{K} \mathrm{mol}^{-1}$ for four cobalt(II) ions and four gadolinium(III) ions. However, upon cooling, the $\chi_{M} T$ product first decreases 10 gradually, and then suddenly turns up at $10 \mathrm{~K}$ and increases sharply to 79.3 emu $\mathrm{K} \mathrm{mol}^{-1}$ at $2 \mathrm{~K}$. There is no sign of a downturn in the $\chi_{M} T$ product at $2 \mathrm{~K}$, unambiguously indicating a ferromagnetic interaction between the metal centres. Fitting the data between 300 and $100 \mathrm{~K}$ with Curie-Weiss law gives a ${ }_{15} C$ value of $62.77 \mathrm{emu} \mathrm{mol}^{-1} \mathrm{~K}$ and a $\theta$ value of $-5.62 \mathrm{~K}$. The $C$ value correponds to a $g$ value of 2.31 , which is again likely to be a result of unquenched orbital momentum from the octahedral cobalt(II) centres and the relatively smaller negative $\theta$ value might be due to the additional compasation 20 of ferromagnetic interactions within metal centres. The magnetisation reaches a magnetic moment of $46.5 \mu_{\text {в }}$ at $2 \mathrm{~K}$ (insert of Figure 6), and the magnetisation looks closer to saturation than in compounds $\mathbf{1}$ and $\mathbf{2}$.

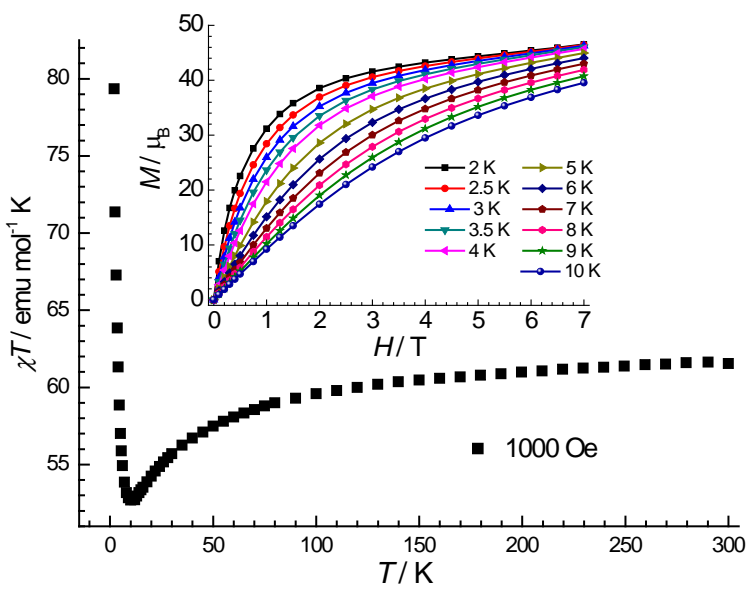

Fig. 6 The $\chi T$ vs.T plot of 3 under 1000 Oe dc field. Inset: the fileddependent magnetization plots at indicated temperatures.

Studies of the ac susceptibility for $\mathbf{1}$ - $\mathbf{3}$ show no slow- relaxation behavior down to $1.8 \mathrm{~K}$, so these are not single molecule magnets. ${ }^{12}$ The large values for the magnetisation 30 make these possible candidates for low temperature magnetic cooling, as the magnetocaloric effect (MCE) can be described as $\Delta S(T) \Delta_{H}=\int[\partial M(T, H) / \partial T]_{H} \mathrm{~d} H .^{3}$ Calculating the entropy changes obtained from the magnetisation data (Figure 7 and S3 and S4) gives values at $4 \mathrm{~K}$ of: for $1,22 \mathrm{~J} \mathrm{~kg}^{-1} \mathrm{~K}^{-1}$; for 2, $3518.5 \mathrm{~J} \mathrm{~kg}^{-1} \mathrm{~K}^{-1}$; for $\mathbf{3}, 23 \mathrm{~J} \mathrm{~kg}^{-1} \mathrm{~K}^{-1}$. The entropy changes in $\mathbf{1}$ and $\mathbf{3}$ are slightly larger than the value reported for the $\left\{\mathrm{Mn}_{4} \mathrm{Gd}_{4}\right\}$ compound $\left(19 \mathrm{~J} \mathrm{~kg}^{-1} \mathrm{~K}^{-1}\right)$ at $4 \mathrm{~K}$.

These experimental entropy change values are approximately half the value that could be achieved if all the 40 spins were aligned parallel. The highest possible entropy is calculable from $R \ln \left(2 S_{\max }+1\right) ;{ }^{3}$ assuming $S_{\mathrm{Co}}=3 / 2$ and $S_{\mathrm{Gd}}=$ $7 / 2$, and that all the spins are parallel would give $S_{\max }=40,26$ and 27 respectively for $\mathbf{1}, \mathbf{2}$ and $\mathbf{3}$. In turn, the calculated entropies would be 36.5 , 33.0 and $33.3 \mathrm{~J} \mathrm{~kg}^{-1} \mathrm{~K}^{-1}$ for $\mathbf{1}, 2$ and 453 , respectively. The reduction of the entropy from the maximum possible could be due to the presence of the anisotropic cobalt(II) centres as magnetic anisotropy is known to reduce MCE.. ${ }^{3,5}$ Further studies such as heat capacity and the magnetic and entropy behavior of analogous compounds 50 of the other lanthanoids are progressing.

In summary, by using simple phosphonates, can make a series of molecular squares which show large MCE at low temperatures. While phosphonates have recently been receiving considerable attention as ligands for making 3d55 metal clusters, ${ }^{13}$ this report is only the second example where they have been used in 3d-4f cages. ${ }^{14}$

We are grateful for the financial support by Marie Curie Fellowship (to YZZ), the EPSRC (UK) and the Royal Society 60 for a Wolfson Merit Award (to REPW).

\section{Notes and references}

${ }^{a}$ School of Chemistry, The University of Manchester, Oxford Road. M13 9PL, Manchester (UK).

${ }_{65}{ }^{b}$ Instituto de Ciencia de Materiales de Aragón, CSIC-Universidad de Zaragoza, Departamento de Fisica de al Materia Condensada, 50009, Zaragoza, Spain.

${ }^{c}$ The Photon Science Institute, The University of Manchester, Oxford Road, Manchester M13 9PL (UK). Fax: (+44)161-275-4616; E-mail: 70 richard.winpenny@manchester.ac.uk

† Electronic Supplementary Information (ESI) available: Selected bond lengths and angles for 1, 2 and 3 and 5. See DOI: 10.1039/b000000x/ ¥ Synthesis of starting materials. 4 were synthesized according to the established methods. ${ }^{24} 5$ were synthesized by refluxing $\mathrm{Gd}_{2} \mathrm{O}_{3}$ (3.62 g, 10 $75 \mathrm{mmol})$ and excess pivalic acid (30 g, $300 \mathrm{mmol})$ at $160{ }^{\circ} \mathrm{C}$ for $5 \mathrm{hrs}$ to form a clear solution. Followed by cooling the solution to room temperature and white precipate came out. $50 \mathrm{ml}$ toluene were added to dissolve the access pivalic acid and filtered in vacuum and $50 \mathrm{ml} \mathrm{n}$ hexane were used to washed the product (yield $13 \mathrm{~g}, 87 \%$ ). Single 80 crystals of 5 were grown in the mixed solution of toluene and n-hexane.

Synthesis of compound 1 to 3.1 were obtained by mixing 4 ( $0.1 \mathrm{~g}, 0.1$ $\mathrm{mmol}), \mathrm{Gd}\left(\mathrm{NO}_{3}\right)_{3}(0.09 \mathrm{~g}, 0.2 \mathrm{mmol})$ and $\mathrm{H}_{2} \mathrm{O}_{3} \mathrm{P}^{t} \mathrm{Bu}(0.014 \mathrm{~g}, 0.1 \mathrm{mmol})$ in $\mathrm{MeCN}(8 \mathrm{ml})$ and stirring at room temperature for a few minutes. The resulting slurry was transferred into a $10 \mathrm{~mL}$ tefflon-lined autoclave, 85 which was heated at $150{ }^{\circ} \mathrm{C}$ for 12 hrs and then cooled into room temperature in a rate of $0.05{ }^{\circ} \mathrm{C} \mathrm{min}{ }^{-1}$. Purple needle-shape crystals of 1 were collected (yield $5 \mathrm{mg}, 4 \%$, based on 4). EA for $\mathrm{C}_{112} \mathrm{H}_{222} \mathrm{Co}_{8} \mathrm{Gd}_{8} \mathrm{~N}_{4} \mathrm{O}_{73} \mathrm{P}_{8}$, found (calc); C 28.90 (28.20), H 4.58 (4.69), Co 
9.91 (9.88), Gd 26.64 (26.37), N 1.04 (1.17) and P 4.96 (5.19). IR (KBr, $\left.\mathrm{cm}^{-1}\right)$ : 2964 (m), 2923 (m), 2875 (m), 1549 (vs), 1483 (s), 1455 (m), 1421 (s), $1377(\mathrm{~m}), 1364(\mathrm{~m}), 1229$ (s), 1060 (vs), $988(\mathrm{~m}), 895(\mathrm{w}), 877(\mathrm{w})$, $830(w), 785(w), 665(w), 612(w), 534(w) .2$ were obtained by mixing 54 (0.1 g, $0.1 \mathrm{mmol}), 5(0.075 \mathrm{~g}, 0.05 \mathrm{mmol})$ and $\mathrm{H}_{2} \mathrm{O}_{3} \mathrm{P}^{t} \mathrm{Bu}(0.014 \mathrm{~g}, 0.1$ $\mathrm{mmol})$ in MeCN (8 $\mathrm{ml}$ ) and stirring at room temperature for a few minutes. The resulting slurry was transferred into a $10 \mathrm{~mL}$ tefflon-lined autoclave, which was heated at $150{ }^{\circ} \mathrm{C}$ for 12 hrs and then cooled into room temperature in a rate of $0.05{ }^{\circ} \mathrm{C} \mathrm{min}$. . Purple needle-shape crystals 10 of 1 were collected (yield $75 \mathrm{mg}, 85 \%$, based on 4). EA for $\mathrm{C}_{104} \mathrm{H}_{198} \mathrm{Co}_{8} \mathrm{Gd}_{4} \mathrm{O}_{50} \mathrm{P}_{6}$, found (calc); C 35.43 (35.34); $\mathrm{H} 5.72$ (5.65); Co 7.68 (7.61); Gd 17.37 (17.29) P 5.33 (5.26). IR (KBr, cm$\left.{ }^{-1}\right) ; 2985(\mathrm{~m})$, 2948 (m), 2838 (m), 1582 (m), 1567 (vs), 1516 (m), 1494 (s), 1467 (m), 1429 (s), 1386 (m), 1372 (m), 1235 (m), 1080 (s), 983 (s), 974 (m), 885 $15(\mathrm{w}), 788(\mathrm{w}), 667(\mathrm{w}), 600(\mathrm{w}), 542(\mathrm{~m}) .3$ were obtained by mixing 4 (0.1 g, $0.1 \mathrm{mmol}), 5(0.1 \mathrm{~g}, 0.075 \mathrm{mmol})$ and $\mathrm{H}_{2} \mathrm{O}_{3} \mathrm{PCH}_{2} \mathrm{Ph}(0.017 \mathrm{~g}, 0.1$ $\mathrm{mmol})$ in $\mathrm{MeCN}(8 \mathrm{ml})$ and stirring at room temperature for a few minutes. The resulting slurry was transferred into a $10 \mathrm{~mL}$ tefflon-lined autoclave, which was heated at $150{ }^{\circ} \mathrm{C}$ for $12 \mathrm{hrs}$ and then cooled into 20 room temperature in a rate of $0.05{ }^{\circ} \mathrm{C} \mathrm{min}{ }^{-1}$. Purple block crystals of 1 were collected (yield $60 \mathrm{mg}, 65 \%$, based on 5). EA for $\mathrm{C}_{116} \mathrm{H}_{174} \mathrm{Co}_{4} \mathrm{Gd}_{6} \mathrm{~N}_{2} \mathrm{O}_{46} \mathrm{P}_{6}$, found (calc); C 37.63 (37.68); $\mathrm{H} 4.81$ (4.74); $\mathrm{N}$ 0.70 (0.76) Co 6.32 (6.38); Gd 25.59 (25.52) P 5.11 (5.03). (KBr, $\left.\mathrm{cm}^{-1}\right)$ : 2966 (m), 2933 (m), 2834(m), 2020 (m), 1583 (s), 1574 (s), 1511 (m), 251478 (s), 1453 (m), 1414 (s), 1364 (m), 1219 (m), 1031 (s), 993 (s), 964 (m), $895(\mathrm{~m}), 834(\mathrm{~s}), 798(\mathrm{~s}), 754(\mathrm{~m}), 687(\mathrm{w}), 606(\mathrm{w}), 546(\mathrm{~m})$.

Crystal data. For $1, \mathrm{C}_{112} \mathrm{H}_{222} \mathrm{Co}_{8} \mathrm{Gd}_{8} \mathrm{~N}_{4} \mathrm{O}_{73} \mathrm{P}_{8}, M=4770.14$, monoclinic, space group $P 2_{1} / n, T=100$ (2) $\mathrm{K}, a=35.6240(18), b=20.7297(10), c=$ 25.0866(13) $\AA, \beta=101.4160(10)^{\circ}, V=18159.3(16) \AA^{3}, Z=4, \rho=1.745$ $30 \mathrm{~g} \mathrm{~cm}^{-3}$, total data 85562, unique data $16004\left(R_{\text {int }}=0.0616\right), \mu=3.737 \mathrm{~mm}^{-}$ 1,1330 parameters, $R_{1}=0.0815$ for $I \geq 2 \sigma(I)$ and $w R_{2}=0.2154$ for all data. For 2, $\mathrm{C}_{104} \mathrm{H}_{198} \mathrm{Co}_{8} \mathrm{Gd}_{4} \mathrm{O}_{50} \mathrm{P}_{6}, M=3534.88$, monoclinic, space group $P 2_{1} / n, T=100(2) \mathrm{K}, a=22.622(3), b=11.6300(17), c=30.189(4) \AA, \beta=$ 97.612(2) ${ }^{\circ}, V=7872.5(19) \AA^{3}, Z=2, \rho=1.491 \mathrm{~g} \mathrm{~cm}^{-3}$, total data 43509,

35 unique data $13830\left(R_{\mathrm{int}}=0.1202\right), \mu=2.609 \mathrm{~mm}^{-1}, 775$ parameters, $R_{1}=$ 0.1227 for $I \geq 2 \sigma(I)$ and $w R_{2}=0.3190$ for all data. For 3, $\mathrm{C}_{116} \mathrm{H}_{174} \mathrm{Co}_{4} \mathrm{Gd}_{6} \mathrm{~N}_{2} \mathrm{O}_{46} \mathrm{P}_{6}, M=3697.61$, monoclinic, space group $P 2_{1} / n, T$ $=100(2) \mathrm{K}, a=13.5500(13), b=29.003(3), c=18.2506(17) \AA, \beta=$ 97.588(2) $, V=7109.4(12) \AA^{3}, Z=2, \rho=1.727 \mathrm{~g} \mathrm{~cm}^{-3}$, total data 43130, 40 unique data $12527\left(R_{\text {int }}=0.0432\right), \mu=3.355 \mathrm{~mm}^{-1}, 1032$ parameters, $R_{1}=$ 0.0660 for $I \geq 2 \sigma(I)$ and $w R_{2}=0.1909$ for all data. For $\mathbf{5}, \mathrm{C}_{180} \mathrm{H}_{342} \mathrm{Gd}_{6} \mathrm{O}_{72}$, $M=4602.04$, monoclinic, space group $P 2{ }_{1} / c, T=100(2) \mathrm{K}, a=$ 21.5396(10), $b=36.3275(17), c=29.8313(14) \AA, \beta=104.3710(10)^{\circ}, V=$ 22612.0(18) $\AA^{3}, Z=4, \rho=1.352 \mathrm{~g} \mathrm{~cm}^{-3}$, total data 123215, unique data $4544344\left(R_{\mathrm{int}}=0.0653\right), \mu=1.812 \mathrm{~mm}^{-1}, 2351$ parameters, $R_{1}=0.0499$ for $I \geq 2 \sigma(I)$ and $w R_{2}=0.1141$ for all data. The data of $\mathbf{1}, 2,3$ and 5 were recorded on a Bruker SMART CCD diffractometer with MoK $\alpha$ radiation $(\lambda=0.71073 \AA)$. The structures were solved by direct methods and refined on $F^{2}$ using SHELXTL. CCDC-XXXXX-XXXXX contain the 50 supplementary crystallographic data for this paper. These data can be obtained free of charge via www.ccdc.cam.ac.uk/conts/retrieving.html (or from the Cambridge Crystallographic Data Centre, 12 Union Road, Cambridge CB21EZ, UK; fax: $\quad(+44) 1223-336-033$; or deposit@ccdc.cam.ac.uk).

55 Magnetic susceptibility measurements of $\mathbf{1}$ to $\mathbf{3}$ were performed with a Quantum Design MPMS-XL7 SQUID. Data were corrected for the diamagnetic contribution calculated from Pascal constants.

1 (a) M. Evangelisti, A. Candini, A. Ghirri, M. Affronte, E. K. Brechin,

$60 \quad$ E. J. L. McInnes, Appl. Phys. Lett. 2005, 87, 072504; (b) R. Shaw, R. H. Laye, L. F. Jones, D. M. Low, C. Talbot-Eeckelaers, Q.Wei, C. J. Milios, S. Teat, M. Helliwell, J. Raftery, M. Evangelisti, M. Affronte, D. Collison, E. K. Brechin, E. J. L. McInnes, Inorg. Chem. 2007, 46, 4968.

652 (a) M. Evangelisti and E. K. Brechin, Dalton Trans., 2010, 4672, and references therein; (b) M. Evangelisti, F. Luis, L. J. de Jongh, M. Affronte, J. Mater. Chem. 2006, 16, 2534.

3 M. Evangelisti, A. Candini, M. Affronte, E. Pasca, L. J. de Jongh, R. T. W. Scott, E. K. Brechin, Phys. Rev. B 2009, 79, 104414.

704 G. Karotsis, M. Evangelisti, S. J. Dalgarno and E. K. Brechin, Angew. Chem. Int. Ed. 2009, 48, 9928.
5 (a) F. Torres, J. M. Herńandez, X. Bohigas and J. Tejada, Appl. Phys. Lett., 2000, 77, 3248; (b) X. X. Zhang, H. L. Wei, Z. Q. Zhang and L. Zhang, Phys. Rev. Lett., 2001, 87, 157203.

756 L. N. Dawe, K. V. Shuvaev, and L. K. Thompson, Chem. Soc. Rev. 2009, 38, 2334.

7 M. Ruben, J. Rojo, F. J. Romero-Salguero, L. H. Uppadine and J.-M. Lehn, Angew. Chem. Int. Ed.,2004, 43, 3644.

8 G. Aromi, A. S. Batsanov, P. Christian, M. Helliwell, A. Parkin, S. 80 Parsons, A. A. Smith, G. A. Timco and R. E. P. Winpenny, Chem. Eur. J. 2003, 9, 5142.

9 I. G. Fomina, M. A. Kiskin, A. G. Martynov, G. G. Aleksandrov, Zh. V. Dobrokhotova, Yu. G. Gorbunova, Yu. G. Shvedenkov, A. Yu. Tsivadze, V. M. Novotortsev, I. L. Eremenko, Zh. Neorg. Khim., 2004, 49, 1463.

10 Harris notation describes the binding mode as $\left[X . Y_{1} Y_{2} \ldots Y_{n}\right]$ where $X$ is the overall number of metal bound by the whole ligand, and each value of $\mathrm{Y}$ refers to the number of metal atoms attached to the different donor atoms. For detail, see R. A. Coxall, S. G. Harris, D.

$90 \quad$ K. Henderson, S. Parsons, P. A. Tasker R. E. P. Winpenny, J. Chem. Soc., Dalton Trans., 2000, 2349.

11 Selected $2 \times 2$ grids

12 R. Sessoli, D. Gatteschi and J. Villain Molecular Nanomagnets, Oxford University Press, Oxford, 2006.

9513 (a) V. Chandrasekhar and S. Kingsley, Angew. Chem. Int. Ed. 2000, 39, 2320. (b) V. Chandrasekhar, L. Nagarajan, R. Clérac, S. Ghosh and S. Verma, Inorg. Chem, 2008, 47, 1067; (c) E. I. Tolis, M. Helliwell, S. Langley, J. Raftery, R. E. P. Winpenny, Angew. Chem., Int. Ed., 2003, 42, 3804; Angew. Chem. 2003, 115, 3934-3938; (d) M. 100 Maheswaran, G. Chastanet, S. J. Teat, T. Mallah, R. Sessoli, W. Wernsdorfer, R. E. P. Winpenny, Angew. Chem., Int. Ed., 2005, 44, 5044; Angew. Chem. 2005, 117, 5172. (e) M. Shanmugam, G. Chastanet, T. Mallah, R. Sessoli, S. J. Teat, G. A. Timco, R. E. P. Winpenny, Chem A Eur-J., 2006, 12, 8777; (f) Langley, S.; Helliwell, M.; Sessoli, R.; Teat, S. J; Winpenny, R. E. P. Dalton Trans...in press; (g) Breeze, B. A.; Shanmugam, M.; Tuna, F.; Winpenny, R. E. P. Chem. Commun., 2007, 42, 5185; (h) S. Khanra, M. Kloth, H. Mansaray, C. A. Muryn, F. Tuna, E. C. Sañudo, M. Helliwell, E. J. L. McInnes, R. E. P. Winpenny, Angew. Chem., Int. Ed., 2007, 46, 5568; Angew. Chem. 2007, 119, 5564. (i) Konar, S.; Bhuvanesh, N.; Clearfield, A. J. Am. Chem. Soc. 2006, 128, 9604. (j) Konar, S.; Clearfield, A. Inorg. Chem. 2008, 47, 5573. (k) Konar, S.; Clearfield, A. Inorg. Chem. 2008, 47, 3489.

14 V. Baskar, K. Gopal, M. Helliwell, F. Tuna, W. Wernsdorfer and R. 115 E. P. Winpenny, Dalton Trans. 2010, 39, 4747. 


\section{TOC}
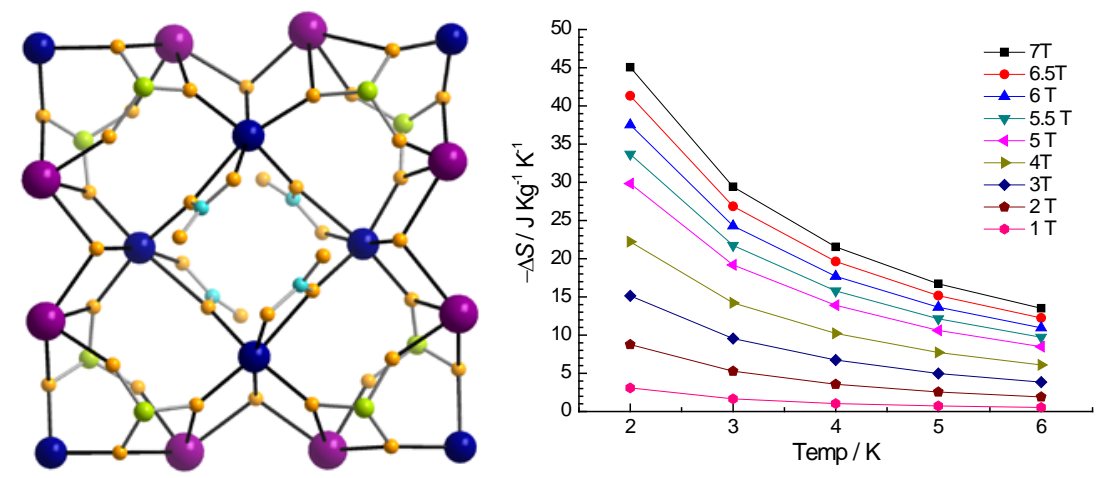

A series of Co(II)-Gd(III) molecular squares with grid-like [4 × 4], [4 × 3] and [3 × 3] structures have been have been synthesized by 5 using phosphonates as bridging ligands. Magnetic studies show them with huge magnetocaloric effect at low-temperatures. 
Supporting Information for

\section{3d-4f Molecular Squares as Magnetic Refrigerants}



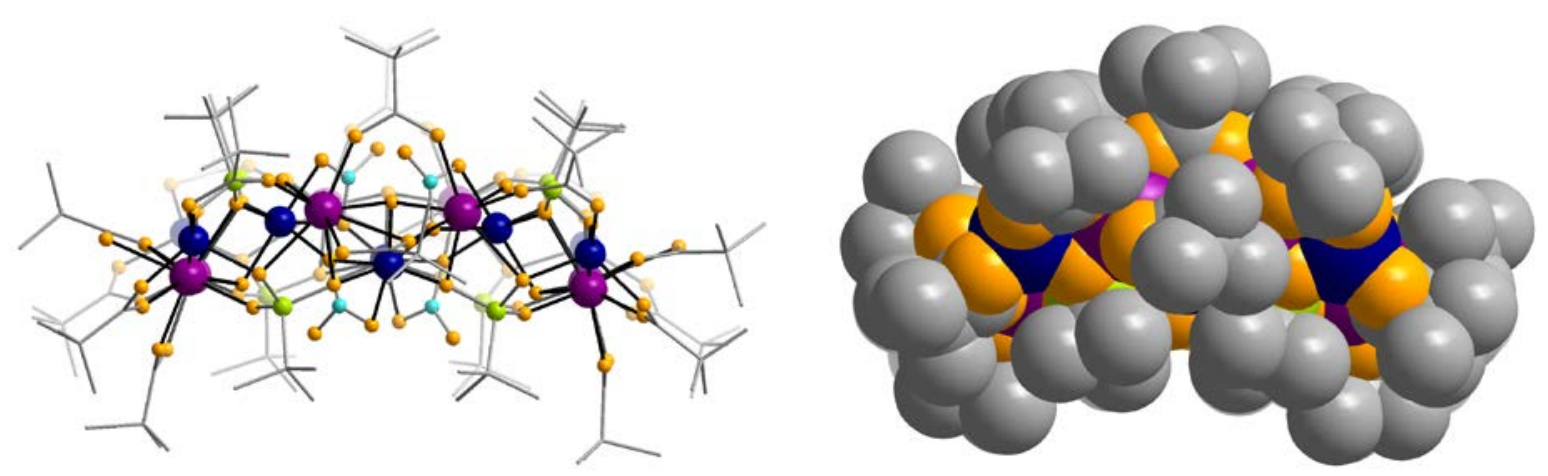

${ }_{5}$ Fig. S1. Side view of compound $\mathbf{1}$ in ball-core (left) and spcae filling fashion (right).
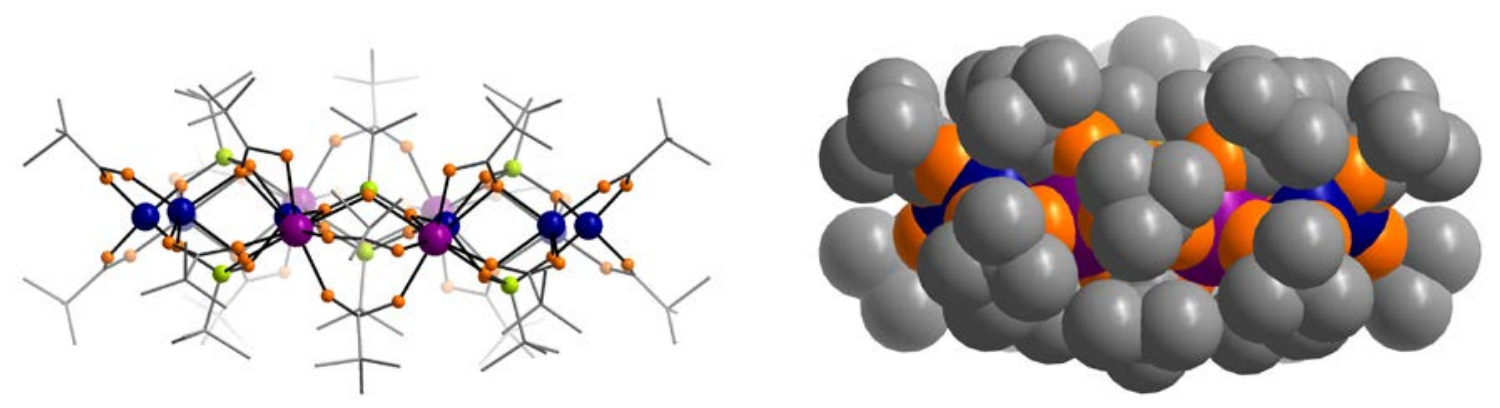

${ }_{10}$ Fig. S2. Side view of compound 2 in ball-core (left) and spcae filling fashion (right).
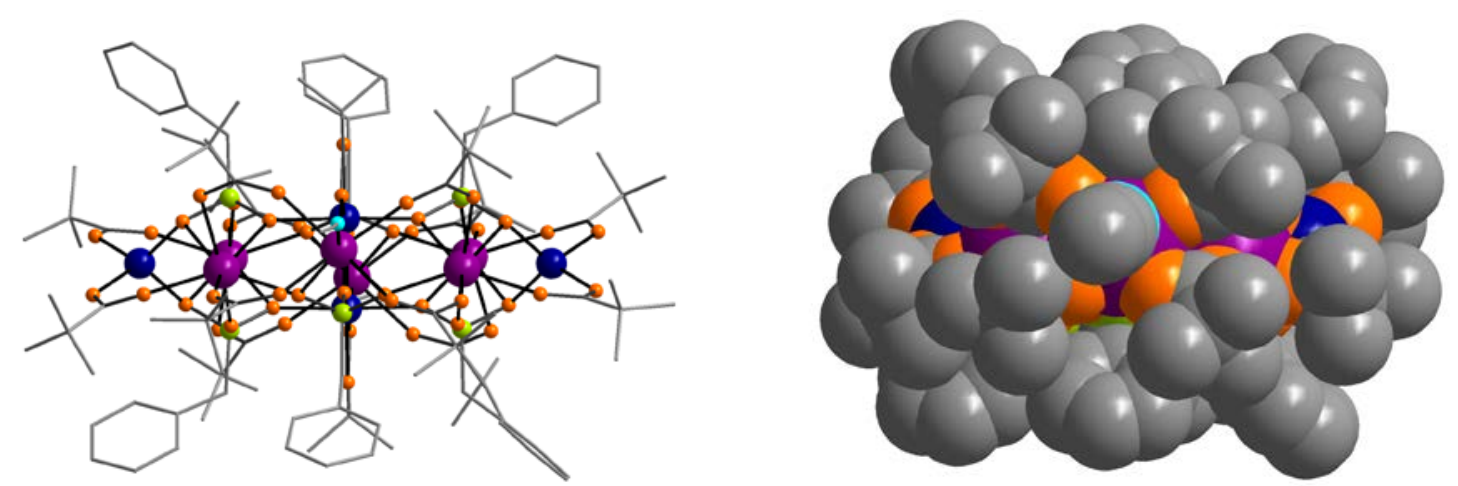

${ }_{15}$ Fig. S3. Side view of compound $\mathbf{3}$ in ball-core (left) and spcae filling fashion (right). 


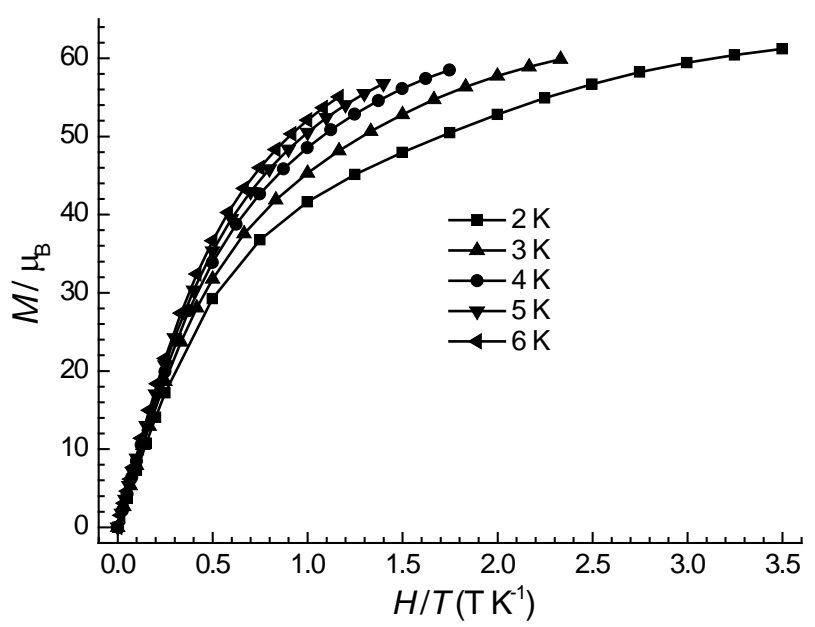

Fig. S4. Reduced magnetisation of $\mathbf{1}$ at indicated temperatures.

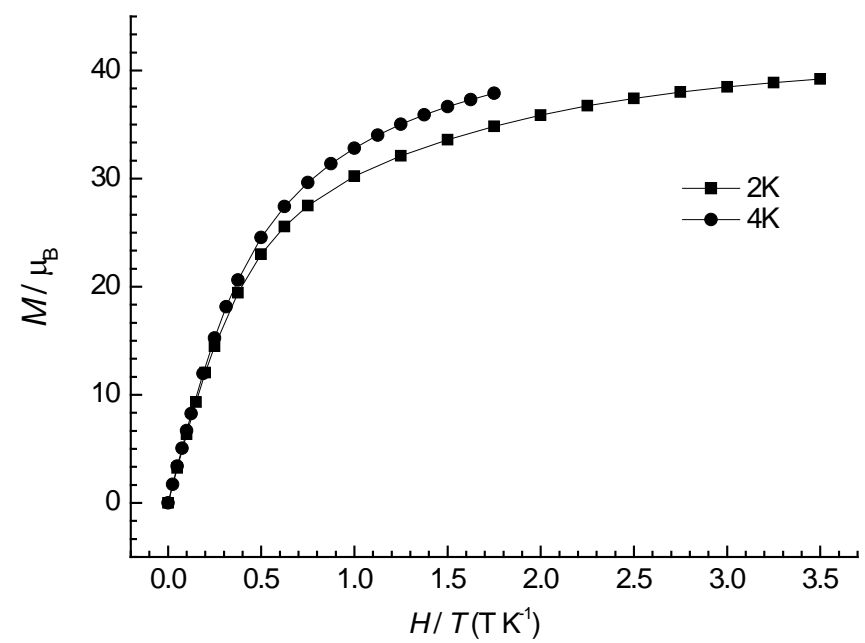

Fig. S5. Reduced magnetisation of $\mathbf{2}$ at indicated temperatures.

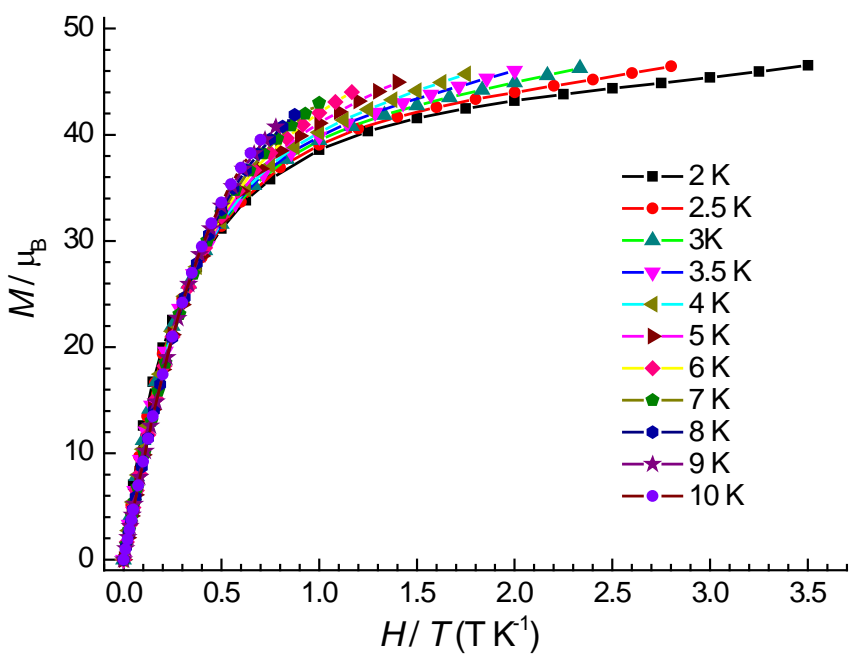

${ }_{10}$ Fig. S4. Reduced magnetisation of $\mathbf{3}$ at indicated temperatures. 